\title{
5 Cognitive, social and emotional development
}

\author{
F. E. WEINERT AND W. SCHNEIDER
}

Every developmental psychologist knows it, many developmental psychologists have explicitly said it over the years, but only a few researchers have paid attention to this fact in their own work: most of our theories of developmental change are not based on empirical study of these changes, but rather on inferences derived from studies of developmental differences between groups of subjects of different ages. It is well known that more than $90 \%$ of published data arise from cross-sectional studies; in contrast, the results from longitudinal studies play only a secondary role.

Why is developmental research so strongly dominated by cross-sectional designs? Three advantages of these designs come first to mind.

The first advantage is a pragmatic one. Modern science is in some ways like a factory for the fast and efficient production of the most data possible. Crosssectional studies offer a very effective medium for fulfilling this requirement. All one needs for a fair chance of getting successful results is a good idea about possible developmental changes or age differences, two, three or four samples from different age groups and a relatively uncomplicated and reliable measurement that avoids floor and ceiling effects. It is only reasonable to expect that some of the many variables measured in childhood will increase with age, that no interesting age differences will be apparent in early and middle adulthood, and that mean decréases in cognitive competence, and increases in behavioural problems, occur in old age. Of course, the characterization of cross-sectional designs as just a vehicle for allowing more and more developmental psychologists to publish more and more articles is too simplistic and biased an evaluation.

The second advantage of cross-sectional designs is that they can characterize and describe typical characteristics across different ages very well. Behavioural and mental changes that are otherwise difficult to describe, and often only moderately correlated with age become, through age-group comparisons, very concise and clear contrastive developmental differences. However, the validity of taking mean age differences as an indicator of individual change is generally an untested presumption that is reasonable only when it applies to universal developmental phenomena that apply to (nearly) all members of our species.

This brings us to the third advantage of cross-sectional designs: they fit into a 
methodological framework arising from a theoretical perspective in which development is conceived as species-specific, universal, and unavoidable. Many developmental phenomena, at least in early childhood and old age, obey such biological rules and constraints or follow a (psycho-)logical sequence.

A characterization of the advantages of cross-sectional designs also implicitly refers to their limits and disadvantages. Assuming that research has the goal of providing scientifically appropriate descriptions, explanations and predictions of cognitive, social and emotional development, there are five problem areas where no satisfactory solution is possible without longitudinal data.

(a) Current developmental laws are not based on data aggregated over changes within individuals, but rather on inferences from mean, variance, and covariance data from two or more age groups. As a consequence, those phenomena for which the detection of developmental change on the basis of mean age differences is not possible or not reliable will be overlooked or misinterpreted. One typical example for this is that underlying the linear increase of average memory performances there are enormous intra- and inter-individual differences in the development of memory skills that were ignored for over a century (Weinert, 1991).

(b) Both the overemphasis on universal development and the resulting cross-sectional methodology reinforce the tendency to reduce the definition and analysis of interindividual differences to acceleration or retardation in the pace of development within a universal, age-related developmental sequence. This means that qualitative differences in developmental change are generally not taken into account, and, more importantly, it is not even possible to test whether there are qualitative differences in patterns of change at all. This is well illustrated by the many studies and debates about possible qualitative developmental differences among normal, disabled and gifted children (Weisz \& Yeates, 1981; Weiss, Weisz \& Bromfield, 1986; Weinert \& Waldmann, 1986).

(c) The third problem area is that cross-sectional designs tend to promote psychological theories of development that are variable- rather than person-centred, because changes in the intra-individual structure or pattern of variables cannot be assessed. Any person-centred claims made on the basis of cross-sectional data are usually empirically untested inferences from the patterns of correlations between independent samples. To illustrate: a focus on variable-centred theories has, no doubt, contributed to the fact that personality development is described either in terms of cognitive models that assume a universal developmental course, or as the sum of changes in single characteristics, such as anxiety, shyness and the like.

(d) We lack theoretical models and empirical studies that address themselves to predicting individual developmental sequences. This is not 
just a problem directed to academic research: it also severely hinders the application of results from developmental research (Kohlberg, LaCrosse \& Ricks, 1972).

(e) A lack of models concerning change at the individual level applies not just to predictions but also to explanations of developmental change. For example, socialization research has been separate from mainstream developmental research for some time, because of its focus on socialization conditions as the explanatory basis for inter- and intraindividual variance in the development of psychological characteristics. Of course, the extent of this variance is largely unknown, because there is a lack of empirically grounded models for the description of intra- and inter-individual developmental variance (Weinert, 1990).

Enough of the familiar complaints about the limitations of cross-sectional designs. Longitudinal researchers are inclined to think that their methodological approach can make a great contribution to developmental psychology. Longitudinal studies, however, at least with the current methodology, can not quickly and satisfactorily solve all of the obvious theoretical problems either. To achieve this, we still need to do a great deal of work. We will argue, though, that this work will pay off. We will address this claim in the rest of the chapter, addressing four points.

\section{TYPES OF LONGITUDINAL ASSESSMENTS OF PSYCHOLOGICAL DEVELOPMENT}

A general problem with evaluating the relevance of longitudinal studies for the description and explanation of human development concerns the definition of what is considered as 'longitudinal'. This term does not describe a single method but a large variety of methods. The spectrum of methods ranges from single-case studies in time-series arrangements to broad-band panel designs including many measurement points and thousands of subjects. The only common denominator of longitudinal research is variation of time and repeated observation of a given entity (cf. Baltes \& Nesselroade, 1979).

Given the lack of definitional clarity, it makes sense to distinguish among different types of longitudinal approaches that seem to follow different goals. There is a general agreement in the developmental literature that two basic types of longitudinal inquiry can be differentiated. One type concerns what Wohlwill (1973) called the 'developmental function', that is, changes in the average and/or individual value of a dependent variable over time. The second type of longitudinal inquiry concerns the issue of individual differences. Here, the major issue is how stable or unstable individual differences remain over time.

It is important to note that the issue of stability or instability of individual differences over time is conceptually independent from the issue of continuity or discontinuity in the developing psychological entity. A continuous developmental function for an entire sample might still occur despite significant 
instability in individual differences. Whether the two are related or not is always an empirical question (cf. Appelbaum \& McCall, 1983). Longitudinal researchers have often overlooked the fact that the continuity of a developmental function and the stability of individual differences over time represent two separate aspects of the same problem (see for a more systematic treatment of this topic Asendorpf 1992a; Schneider, 1989).

How can we relate the existing types of longitudinal studies to these two aspects of inquiry? A review of longitudinal studies (Schneider \& Edelstein, 1990; Verdonik \& Sherrod, 1984) reveals that the majority of studies focus on the stability issue. That is, these studies concentrate on the question of whether individual subjects maintain approximately the same relative rank ordering within their group over time. Differences among studies of this type concern how the stability concept is treated: whereas some researchers differentiate between the stability of a variable and the stability of an individual (Wohlwill, 1973), others define stability of the individual as ipsative stability, that is, the persistence of a pattern of variables for an individual subject over time (cf. Asendorpf \& Weinert, 1990; Asendorpf \& van Aken, 1991; Rutter, 1987).

In a few longitudinal studies the second aspect of longitudinal inquiry, that is, the issue of continuity/discontinuity of development has been investigated. Here, the major difficulty is that the same instruments must be used on each testing occasion, and one must be able to prove that the instruments do not change their meaning over time (cf. Kagan, 1980; Magnusson, 1981). Asendorpf $(1992 a)$ has recently suggested a methodology for studying this problem empirically. Other approaches include (nomothetical) single-case studies, investigating the growth of a specific psychological function over an extended period in time; and so-called 'micro-genetic' longitudinal studies, based on a few subjects and focusing on quantitative as well as qualitative changes in a specific developmental area (for a more systematic characterization of this treatment and for some illustrative examples, see Siegler \& Jenkins, 1989; Siegler \& Crowley, 1991).

\section{WHAT KIND OF PSYCHOLOGICAL KNOWLEDGE DOES LONGITUDINAL RESEARCH GENERATE?}

What is the 'new' knowledge that longitudinal studies can add to that already acquired through cross-sectional research? As emphasized by Baltes and Nesselroade (1979), longitudinal research can improve our understanding of developmental processes because it is particularly suited to describe and explain individual development in several aspects: (a) intraindividual change can be directly identified; (b) causes of intra-individual change can be analysed; (c) inter-individual differences in intra-individual change can be directly identified; (d) possible causes of inter-individual differences in intra-individual change can be analysed, and (e) interrelationships among classes of behaviour and their common patterns of change can be assessed. Another advantage of longitudinal 
studies over cross-sectional designs is that individual differences in one domain can be predicted from individual differences in another domain. For example, with longitudinal designs one can explore the impact of early risk factors like delay in language acquisition (domain 1) on later reading and writing skills (domain 2).

In our view, it is questionable whether large-scale, broad-band longitudinal analyses can provide new information on general or universal developmental trends. The same results could probably be obtained via cross-sectional studies (for specific problems see Schaie, 1989). Accordingly, the costs of longitudinal research may appear too great for researchers predominantly interested in the exploration of universal developmental trends (cf. De Ribaupierre, 1989).

However, there is no doubt that the longitudinal approach is the only suitable method for investigating individual differences and their stability over time. That is, longitudinal research must be used to assess whether development takes the same form for all individuals. As already mentioned above, the issue of the continuity/discontinuity of development is conceptually unrelated to the issue of stability/instability of individual differences. The relationship between these two aspects of development can only be tested empirically: although it could be that a continuous developmental function (e.g. a linear increase in competence over time) is accompanied by stable inter-individual differences over time, this need not be the case. The exact nature of this relationship can only be assessed via longitudinal designs.

Another advantage of the longitudinal studies is that the single-case and microgenetic studies mentioned above provide tools for investigating the issue of identification of intra-individual change in specific psychological functions. When planned carefully, such studies give important information on the typical developmental course of a psychological function that is based on growth curve patterns aggregated across several individuals. Statistical models (growth curve models) that suggest the type of the developmental function in question (e.g. linear versus nonlinear), and that are helpful in identifying underlying causes of individual differences in intra-individual change can be used with these data (see Bryck \& Raudenbush, 1987). Information of this kind cannot be obtained through cross-sectional analyses.

Fine-grained longitudinal analyses of this type are generally restricted to small-scale, short time-span investigations. Microgenetic studies are not feasible over a long time period or with many subjects.

A final important advantage of longitudinal designs is that they allow the estimation and testing of developmental models. Usually, predictions/hypotheses concerning stability and change in patterns of variables are derived from cross-sectional research and tested through longitudinal assessments. The importance of this approach for the acquisition of new knowledge about longterm developmental trends has been demonstrated in many cognitive and social domains (cf. Magnusson, 1988). 


\section{EXAMPLES OF LONGITUDINAL RESEARCH ON COGNITIVE AND SOCIAL DEVELOPMENT BASED ON LONGITUDINAL DATA}

In the following, we will discuss a few selected examples that we think show how longitudinal research has enriched our knowledge of developmental processes.

\section{Consistency and stability of memory development in early childhood}

The first example concerns the development of cognitive processes and is taken from the longitudinal study on the genesis of individual competencies (LOGIC) which has been conducted at our institute (cf. Weinert \& Schneider, 1989). The study started in 1984 with about 200 4-year-old children who have been followed annually. From the very beginning, children were tested with a broad range of measures assessing cognitive skills like intelligence, memory, and problem solving, motivational tendencies, and social-emotional constructs like social inhibition or social competence in various settings.

One question concerned the development of memory in children. At the first measurement point, memory span, performance in a sort-recall task and memory for scripted texts (e.g. a birthday party, playing with friends) were assessed. When inter-correlations among these memory measures were computed for this first measurement point (see Table 5.1), it was found that, with the exception of the inter-relationship between recall for the two stories, intertask consistency in pre-schooler's memory performance was remarkably low (cf. Weinert, Schneider \& Knopf, 1988).

Table 5.1. Intercorrelations among various memory performance
measures obtained for four-year-old children $(N=185)$
\begin{tabular}{lccc}
\hline Variables & $(2)$ & $(3)$ & $(4)$ \\
\hline 1. Memory span & .21 & .20 & .25 \\
2. Recall in a sort-recall task & & .23 & .36 \\
3. Text recall 1 (birthday party) & & .64 \\
4. Text recall 2 (playing with friends) & & & - \\
\hline
\end{tabular}

Source: Data from Weinert et al. 1988, p.59.

Over the subsequent pre-school and kindergarten years, the same measures were repeated at least twice. An inspection of the means and standard deviations suggested an approximately linear increase in performance for most memory measures. However, the analysis of synchronic (cross-sectional) and diachronic 


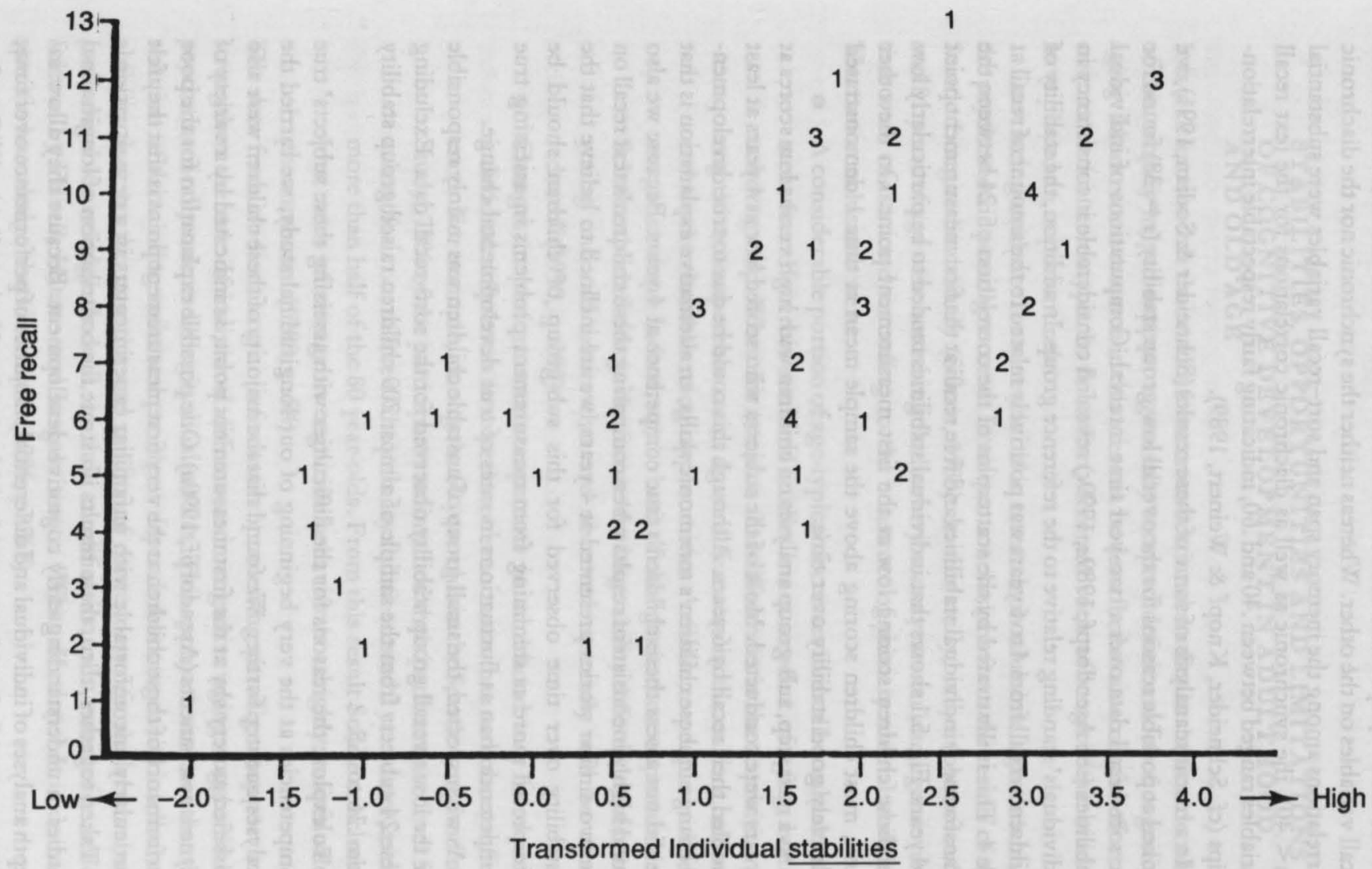

Fig. 5.1. Scatterplot of the bivariate distribution of children's individual stabilities in free recall and their initial scores in this variable. (Data from Schneider \& Sodian, 1991, p.23.) Note Numbers displayed on scatterplot indicate number of observations at each position. 
(across-measurement points) correlations revealed different patterns of stability for the memory span and sort-recall variables on the one hand, and the text recall variables on the other. Whereas neither the synchronic nor the diachronic correlations among the memory span and sort-recall variables were substantial $(r s<.40)$, the synchronic as well as diachronic correlations for the text recall variables ranged between .40 and .60 , indicating fairly respectable interrelationships (cf. Schneider, Knopf \& Weinert, 1989).

In a recent reanalysis of some of these results (Schneider \& Sodian, 1991), we looked at possible reasons for the overall low group stability $(r=.38)$ found for the sort-recall data over a two-year time interval. Computations of individual stabilities (see Asendorpf, 1989a, 1990c) revealed considerable inconsistency in individuals' standing relative to the reference group. In addition, the stability of children's recall from 4 to 6 years was positively related to the amount of recall at age 4 . This is illustrated by the scatterplot of the correlation of 24 between the (transformed) individual stabilities and free recall at the first measurement point at 4 years. Fig. 5.1 shows that individual stabilities tended to be particularly low for those children scoring low at the first measurement point. On the other hand, most children scoring above the sample mean at time 1 demonstrated relatively good stability over time.

As a next step, sub-group analyses on children with high versus low scores at 4 years were conducted. Most of the subjects who scored low at 4 years at least doubled their recall by 6 years. Although this could be due to true developmental change in these children's mnemonic skills, an alternative explanation is that we did not assess these children's true competence at 4 years. Because we also found highly inconsistent results when comparing these children's text recall on the two similar stories presented at 4 years, we are inclined to believe that the instability over time observed for this sub-group of children should be interpreted more as stemming from measurement problems in assessing true competence than as fluctuations in rates of true developmental change.

As we suspected, the small group of unstable children was mainly responsible for the low overall group stability observed for the sort-recall data. Excluding these 24 subjects from the sample of almost 200 children raised group stability from .36 to .65 .

To explore the reasons for the difficulties with assessing these subjects' true competencies at the very beginning of our longitudinal study, we carried the analyses one step further. We found that the majority of these children were also classified as very shy at the first measurement point, as indicated by a variety of shyness assessments (Asendorpf, 1990a). One possible explanation for the poor performance of these children at the very first measurement point is that they felt particularly uncomfortable with unfamiliar experimenters in a new situation.

Taken together, then, these results illustrate the contribution of longitudinal studies in understanding early cognitive development. Because they allow indepth analyses of individual and differential stabilities of performance over time, they can provide us with a comprehensive picture of inter-individual differences 
in developmental change, thereby going beyond the information obtained from cross-sectional studies.

\section{STABILITIES, OPPORTUNITIES AND LIMITATIONS OF COGNITIVE DEVELOPMENT IN ADULTHOOD AND OLD AGE}

It is well known that the results from cross-sectional studies in the first decades of this century helped support a generally accepted deficit model of cognitive aging. More recent research in this area can be described as a successful effort to overcome this stereotype. In this effort, different sorts of longitudinal studies have played an important role.

Convincing evidence for a 'new look' in research on adult intelligence within the psychometric paradigm comes from two conclusions from the results of the Seattle Longitudinal Study (Schaie, 1983). In this study, subjects between 25 and 81 years of age were tested regularly every seven years on intelligence tests that were constructed according to the construct of primary mental abilities. The two conclusions were:

- A considerable portion of age-typical decreases in intellectual achievement found in cross-sectional studies is not an effect of aging, but of cohort group. What this means is that differences in the acquisition of cognitive competence result from differences in the culture, school, and work-related learning opportunities available to people in different generations. Indeed, on the basis of changes in these opportunities, Schaie expected that in the future 'the large ability differences between young and old adults that are observed currently will be much reduced' (1990, p. 299).

- Changes in performance competence in adulthood may be due to individual differences in experience even more than to cohort differences. For example, among the 60 year-olds in the Seattle Longitudinal Study, $75 \%$ of the participants maintained their performance level for at least four out of five of the primary abilities tested 7 years later, as did more than half of the 80 year-olds. From this result Schaie concluded 'that rates of change in cognitive behavior is a highly individuated phenomenon' (1989, p. 84).

The data from studies using an information processing paradigm support and strengthen the role of individual differences in cognitive aging suggested by psychometrically oriented longitudinal studies. This approach assumes that the solution of demanding tasks and problems depends less on general intellectual abilities than on the quantity and quality of content-specific declarative and procedural knowledge. Indeed, in their modification of a conclusion made famous by Flavell, Hatano and Inagaki wrote: 'What develops? It is domain specific knowledge that develops" (1986, p. 267).

It is often assumed that the exclusive importance of domain specific 
knowledge is confirmed by studies comparing novices and experts. Many cognitive psychologists interpret novice-expert performance differences (where subjects are equated for IQ, memory span and education) exclusively as a consequence of the experts' increased and different content-specific knowledge within a particular domain (e.g. chess, physics, radiology). This explanation, however, is not accurate, because interpreting results from such contrastive studies runs into the same problems as interpreting results from cross-sectional studies. Specifically, it is not clear whether differences between novices and experts are valid indices for individual processes of change. In fact, it is quite likely that group differences between novices and experts arise because some proportion of novices drop out during the long process of acquiring expertise, perhaps because the cognitive demands are too hard, or because the long term motivation is missing. Thus, novices and experts may differ in more than just the possession of rich domain specific knowledge. Thus, to explain the influence of knowledge acquisition on changes in cognitive performance at an individual level, longitudinal studies are necessary. Different sorts of longitudinal methodologies can be useful in this context.

First of all, there are quasi-longitudinal designs, in which pre-experimental knowledge is carefully analysed. In this case, both the intra-individual knowledge profile and inter-individual differences in knowledge are predicted to play an important role. Not only will meaningful individual differences in the solution of cognitive tasks depend on how comprehensive domain specific expertise is but an individual's performance level will remain more stable with increasing age when an elaborated knowledge base can be used. This hypothesis has generally been confirmed in empirical studies (Knopf, Kolodziej \& Preussler, 1990). It is both theoretically and pragmatically interesting that such expert skills can help compensate for age-related deficits in basic cognitive functions in the production of more complex outcomes (Salthouse, 1984).

A second longitudinal procedure is to provide systematic and controlled training in a specific expertise. Because of the enormous amount of effort required, this is usually realized in a single subjects design. A good example of such a design is a study by Staszewski (1990), who turned a single subject into a digit span memory expert by systematically training him for more than five years. Beginning with an average span of 8 digits, the subject finally achieved a span of 104 numbers, correctly repeated after a single presentation. Even more interesting than this incredible achievement, is the theoretically oriented study of the memory skills that the subject acquired from a mixture of practice, knowledge and strategies.

An example of a third variation of longitudinal designs shows how the results of such single case studies can be generalized to all age-groups. This example is of testing-the-limits experiments with unselected samples of different ages (Kliegl, Smith \& Baltes, 1989). The experiments were concerned with extending word span through combining and automatizing different mnemonic techniques. 


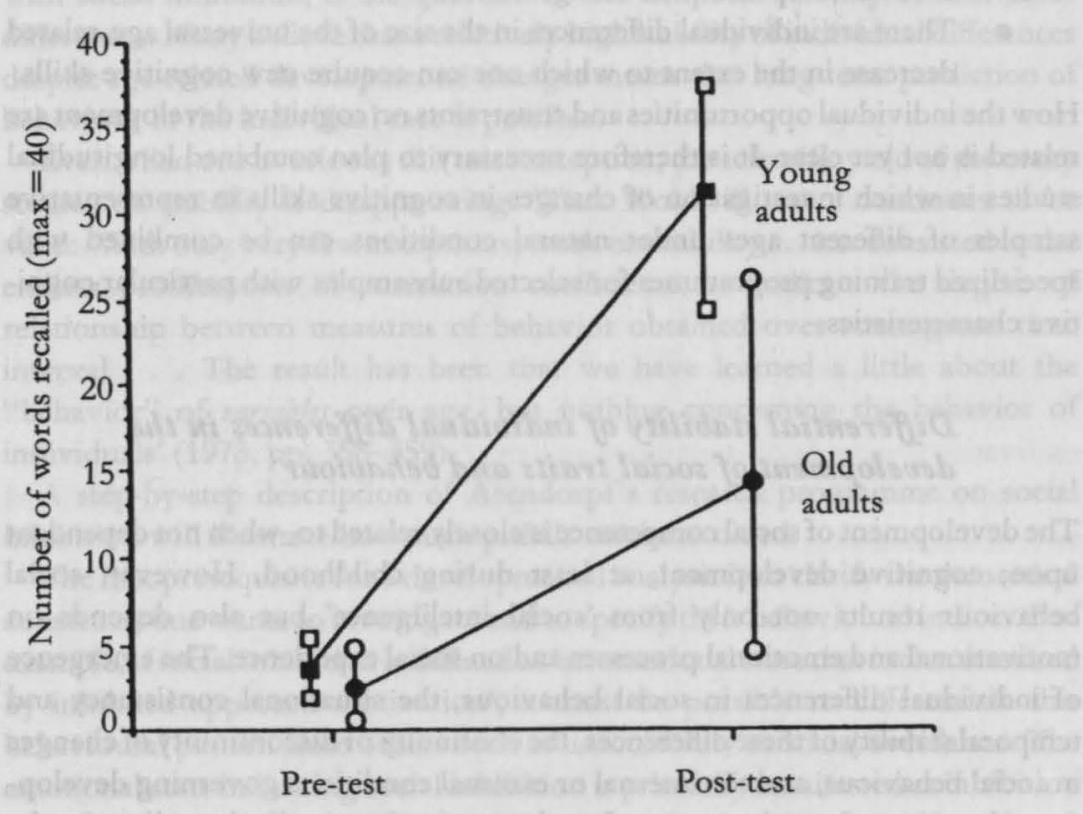

Fig. 5.2. Age $\times$ time of assessment interaction for serial recall of words in Experiment 1 (combining performance at $10 \mathrm{~s}$ and $4 \mathrm{~s}$ rates), showing the magnification of age and individual differences at post-test. (Bar lines indicate range of scores.) (Data from Kliegl et al., 1989, p.250.)

Fig. 5.2 shows that young and old adults showed equivalently large training effects and both achieved a criterion of outstanding performance. None the less, clear age differences in the extent to which maximum performance could be achieved were apparent, so that improvements in memory performance at the end of training by young and old subjects equated for IQ no longer overlapped. This pattern of results provides good evidence both for the possibility of ageindependent improvement in memory performance as a consequence of acquiring expertise, and also for age-dependent limitations in the learning skills necessary for acquiring expertise. As Fig. 5.2 also makes clear, individual differences in these age-related limitations were also quite large.

If one summarizes the findings from the longitudinal studies on cognitive aging mentioned here as well as many others, some general conclusions about the meaning of individual differences for cognitive development in adulthood are possible.

- There are age-invariant individual differences in the cognitive potential to acquire new cognitive competencies.

- There are individual differences in domain specific zones of proximal 
change that seem to depend on general intellectual resources as well as on domain specific knowledge.

- There are individual differences in the size of the universal age-related decrease in the extent to which one can acquire new cognitive skills. How the individual opportunities and constraints on cognitive development are related is not yet clear. It is therefore necessary to plan combined longitudinal studies in which investigation of changes in cognitive skills in representative samples of different ages under natural conditions can be combined with specialized training programmes for selected subsamples with particular cognitive characteristics.

\section{Differential stability of individual differences in the development of social traits and behaviour}

The development of social competence is closely related to, when not dependent upon, cognitive development, at least during childhood. However, social behaviour results not only from 'social intelligence' but also depends on motivational and emotional processes and on social experience. The emergence of individual differences in social behaviour, the situational consistency and temporal stability of these differences, the continuity or discontinuity of changes in social behaviour, and the internal or external conditions governing developmental patterns have been a preferred area for longitudinal studies. In the following description of some basic questions and results, we will rely heavily on the work of Jens Asendorpf. This work stems from the Munich Longitudinal Study on the Genesis of Individual Competencies (LOGIC) mentioned above.

The following constructs were assessed in the LOGIC study of social development:

Social competence This is a set of skills for interacting adequately and effectively with other people in the environment and an ability to influence the behaviour of another person so that it matches one's own interests. This construct was measured in the kindergarten group as well as in dyadic play with familiar and unfamiliar peers.

Social inbibition This is an individual disposition to react by inhibiting interactive behaviour in certain social situations. This construct was measured in the kindergarten group, in the school class, and in a standardized laboratory situation. In addition, children's aggression in peer groups was both directly observed and was rated by the parents.

Personality profile This is as measured by the California Child Q Sort. It was measured each year on the basis of ratings by the preschool/kindergarten teacher. In the discussion that follows, we will focus on some data concerning the development of social inhibition. 
A central concern of most longitudinal studies, including those concerned with social inhibition, is the question of the temporal stability of individual differences. Many believe that a relatively high stability of individual differences despite age-related developmental changes means that long-term prediction of behaviour in the individual case is possible.

Even when one overlooks this misconception, the scientific yield of the many studies on stability is disappointing. What Wohlwill wrote continues to be valid: 'With only very few exceptions, work on stability ... has consisted in the endless proliferation of correlation coefficients, to indicate the degree of relationship between measures of behavior obtained over some given time interval ... The result has been that we have learned a little about the "behavior" of variables over age, but nothing concerning the behavior of individuals' (1973, pp. 358-359).

A step-by-step description of Asendorpf's research programme on social inhibition will illustrate how such pitfalls can be avoided.

The first prerequisite for a developmental analysis is to clarify the theoretical constructs one wants to investigate and to specify their behavioural indices. For example, if social inhibition is defined as 'an emotional state that is characterized by inhibited approach motivation', it must be possible to differentiate this behavioural pattern from others such as unsociability or social avoidance. The emotional state indicating social inhibition is primarily manifested as inhibition toward strangers and as inhibition in social-evaluative situations (Asendorpf, $1989 c$, in press).

The second pre-requisite for developmental analysis is an empirical test of whether the chosen behavioural indices tap the same construct at different ages. Asendorpf (1992) showed that there is a relatively perfect continuity across age in how shyness and social inhibition are expressed and are perceived.

The third step is the investigation of the general developmental sequence of the trait. In the case of social inhibition, it is possible to discern three stages: 'In the first stage, inhibition towards adult strangers is aroused by rather simple physical characteristics of the situation ... and social evaluative inhibition is restricted to conditioned cues for punishment of frustrative non-reward. . . . In the second stage, beginning around the age of 20 months, the emerging new ability of spontaneous perspective taking arouses inhibitions towards peer and adult strangers due to a perceived uncertainty of the strangers' intentions, and social-evaluative inhibition due to the anticipation of negative or insufficiently positive social evaluations. Later on, in the third stage of the development of inhibition, the reflections about one's own self-presentation reaches awareness and becomes particularly intense during adolescence' (Asendorpf, in press).

Inter-individual differences in inhibition toward strangers are very stable over time. This is based not only on a systematic review of the literature (Asendorpf, 1989b, p. 79), but also on the results of the LOGIC study (Asendorpf, 1990a, 1993). The average, that is aggregated stability increases with increasing age from the second year of life on, and decreases only temporarily in adolescence. 
Inhibition toward strangers is a personality trait that shows considerable situational and, as noted above, temporal consistency. This trait, however, loses its behavioural effect when situations and persons become more familiar, for example, in a kindergarten or school class. Table 5.2 shows the relevant results for this point from the LOGIC study (Asendorpf, 1990b, p. 11; Asendorpf, 1993).

Whereas the stability of individual differences in inhibition toward strangers remained stable across five measurement points, social inhibition in kindergarten and school classes was less stable, and decreased continuously between measurement points. As the correlation pattern shows, the consistency between behaviour with strangers and behaviour with familiar classmates also changed. In the first year of kindergarten and in the first year of grade school (when classmates were unfamiliar) there was a clear positive relation between inhibition toward strangers and inhibition toward classmates. However, in the third year of kindergarten and at the end of the second grade (when classmates were familiar), these correlations were no longer significant.

The temporal stability of individual differences in a sample should be assessed not only at the aggregate level, but individual social inhibition scores should also be used to assess differential stability, that is individual differences in stability (Asendorpf, 1989a). From a developmental perspective, data concerning the stability of inter-individual differences in intra-individual change are especially interesting because they would make the identification of differential developmental patterns possible. Asendorpf (1992b) showed that the stability of children's peer network was positively related to the one-year stabilities of their inhibition toward peers (as judged by their parents) for three successive oneyear intervals. This finding demonstrates that the stability of individual characteristics can be profitably related to an individual's environmental stability.

The steps of the research programme described thus far have all been variable-centred, that is, they have been focused on the variable 'social inhibition', not on the organization of the personality within which social inhibition is but one trait among many. To tap the important person-centred level, Asendorpf used a Q-sort profile procedure. The Q-sort profiles showed large inter-individual differences in temporal stability, producing individual stability coefficients that, in studies from Asendorpf and van Aken (1991), varied from -.09 to .83 .

How can one explain the large interindividual differences in the stability of personality patterns? A first answer to this question comes from the surprisingly strong correlations between a measure of two-year stability of the personality profile and a profile of the 'ideal child' provided by kindergarten teachers. In general, the more a child's profile approached that of the 'ideal child', the more stable was that child's profile over time (Asendorpf, 1990b).

In a further analysis of data from the LOGIC project, it was possible to show that children with socially inhibited behaviour increasingly tended to prefer 


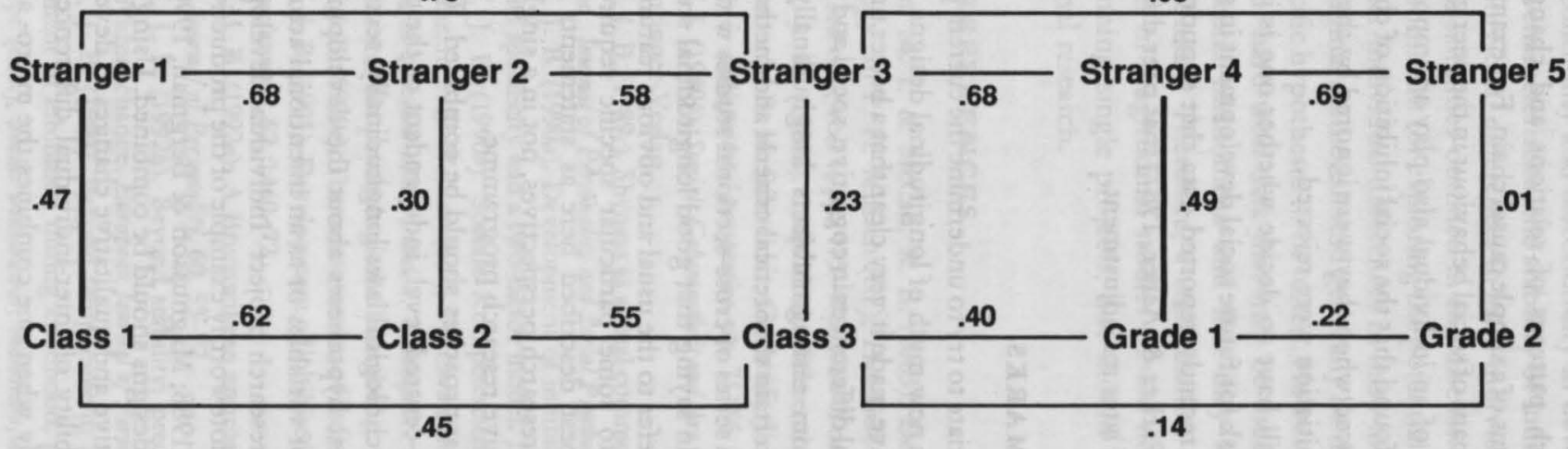

Table 5.2. Stabilities and consistencies of social inhibition towards strangers and classmates. (Data from Asendorpf, 1990a, p.11.) 
passive solo activities to social involvement. This finding suggests that an initially independent tendency to be socially inhibited becomes increasingly associated with unsociability on the overt behavioural level (Asendorpf, 1991).

One should not interpret such patterns of relations and changes in the features of social behaviour in terms of a simple causal chain. For example, social inhibition is not the only determinant of social behaviour in the peer group. The social skills and the social status of an individual also play an important role. Asendorpf (1990a), for example, found that the social inhibition of children in a classroom became more pronounced when they were ignored by their peers or when their attempts at contact initiation were rejected.

Future longitudinal studies will have to decide whether one is justified in speaking of children who are at risk for future social development in such cases. To be sure, Hymel et al. (1990) recently reported data that supported earlier findings (Kohlberg et al., 1972; Parker \& Asher, 1987) that peer difficulties in early childhood are predictive of later maladjustment.

\section{CONCLUDING REMARKS}

It would be completely inappropriate to try to undermine the current preference for cross-sectional designs with a new myth of longitudinal designs. The three examples we presented should have made it very clear that a better understanding of development and individual differences in cognitive, social and emotional areas does not arise simply from testing subjects longitudinally. Rather, longitudinal studies must fulfill certain theoretical criteria and methodological standards to avoid being simply a series of cross-sectional studies with repeated measures spread out over time. In saying that good longitudinal studies must meet certain criteria, we do not refer to the usual and obvious features of good empirical research, but rather to some particular specific requirements of longitudinal designs, that are best described here as statements about the necessity of combining different research perspectives, not in a single study of course, but within a comprehensive research programme.

Variable- and person-centred approaches should be combined. This allows two things: first, on the variable-centred level, independent of the person as a structural entity, one can test psychological laws longitudinally; second, on the person-centred level, one can test hypotheses about the development of the person as an organized pattern of variables or as an intentional actor and selfreflective subject. The Swedish research project 'Individual development and adjustment' is a convincing and noteworthy example of the productivity of this research approach (Magnusson, 1988; Magnusson \& Bergman, 1990).

Single-subject and large-scale designs should be combined. Using longitudinal data to fully analyse quantitative and qualitative changes in developmental functions, and to study the stability of inter-individual differences in intraindividual change is possible only when one combines the micro- and macrogenetic levels. 
The potential of longitudinal research for explaining change and stability has not been sufficiently exploited. Whereas longitudinal designs are preferred for describing continuity and discontinuity in developmental functions, changes in individual characteristics, the stability of individual differences, and variations of inter-individual differences in intra-individual changes, the few examples of research possibilities outlined in the discussion of social development should serve as a stimulant for exploring the potential of longitudinal designs to further explain inter-individual differences in intra-individual change.

Longitudinal studies should generally be theoretically grounded and should allow specific hypotheses to be tested. However, longitudinal data also provide a source of hard-won data that may be used to uncover new or overlooked developmental phenomena and that may lead to the formulation of new theoretical ideas. Therefore, a combination of confirmatory and exploratory procedures in longitudinal studies should not only be an important criterion when planning single projects, but should become a dominant goal for all longitudinal research.

\section{REFERENCES}

Appelbaum, M. I. \& McCall, R. B. (1983). Design and analysis in developmental psychology. In P. H. Mussen (ed.), Handbook of child psychology: bistory, theory, and methods (3rd ed.), vol. 1, pp. 415-476. New York: Wiley.

Asendorpf, J. B. (1989a). Individual, differential, and aggregate stability of social competence. In B. H. Schneider, G. Attili, J. Nadel \& R. Weissberg (eds.), Social competence in developmental perspective, pp. 71-86. Dordrecht, NL: Kluwer.

Asendorpf, J. (1989b). Soziale Gebemmtheit und ibre Entwicklung. Berlin, Heidelberg, New York: Springer-Verlag.

Asendorpf, J. B. (1989c). Shyness as a final common pathway for two different kinds of inhibition. Journal of Personality and Social Psycbology, 57, 481-92.

Asendorpf, J. B. (1990a). Development of inhibition during childhood: Evidence for situational specificity and a two-factor model. Developmental Psychology, 26, 721-30.

Asendorpf, J. B. (1990b). Soziale Kompetenzentwicklung zwischen dem 4. und 8. Lebensjahr. In F. E. Weinert (ed.), Die Entwicklung kognitiver, motivationaler und sozialer Kompetenzen qwischen dem 4. und 8. Lebensjabr. Paper Nr. 16/1990. München: MaxPlanck-Institut für psychologische Forschung.

Asendorpf, J. B. (1990c). The measurement of individual consistency. Metbodika, 4, 1-23. Asendorpf, J. B. (1991). Development of inhibited children's coping with unfamiliarity. Cbild Development, 62, 1460-72.

Asendorpf, J. B. (1992a). A Brunswikean approach to trait continuity: application to shyness. Journal of Personality, 60, 53-77.

Asendorpf, J. B. (1992b). Beyond stability: predicting interindividual differences in intraindividual change. European Journal of Personality, 6, 103-17.

Asendorpf, J. B. (1993). Beyond temperament: a two-factorial coping model of the development of inhibition during childhood, pp. 265-89. In K. H. Rubin \& J. B. Asendorpf (eds.), Social withdrawal, inbibition, and shyness in cbildhood. Hillsdale, EJ: Erlbaum. 
Asendorpf, J. B. (in press). Social inhibition: A general-developmental perspective. In J. Pennebaker \& H. C. Traue (eds.), Emotional expression and inhibition in health and illness. Toronto, Canada and Lewiston, NY: Hogrefe and Huber.

Asendorpf, J. B. \& van Aken, M. A. G. (1991). Correlates of the temporal consistency of personality patterns in childhood. Journal of Personality, 59, 689-703.

Asendorpf, J. \& Weinert, F. E. (1990). Stability of patterns and patterns of stability in personality development. In D. Magnusson \& L. R. Bergman (eds.), Data quality in longitudinal research, pp. 181-197. Cambridge: Cambridge University Press.

Baltes, P. B. \& Nesselroade, J. R. (1979). History and rationale of longitudinal research. In J. R. Nesselroade \& P. B. Baltes (eds.), Longitudinal research in the study of bebavior and development, pp. 1-39. New York: Academic Press.

Bryk, A. S. \& Raudenbush, S. W. (1987). Application of hierarchical linear models of assessing change. Psycbological Bulletin, 101, 147-58.

De Ribaupierre, A. (1989). Epilogue: on the use of longitudinal research in developmental psychology. In A. De Ribaupierre (ed.), Transition mechanisms in cbild development, pp. 297-317. Cambridge: Cambridge University Press.

Hatano, G. \& Inagaki, K. (1986). Two courses of expertise. In H. Stevenson, H. Azuma \& K. Hakuta (eds.), Child development and education in Japan, pp. 262-272. New York: Freeman.

Hymel, S., Rubin, K.H., Rowden, L. \& LeMare, L. (1990). Children's peer relationships: longitudinal prediction of internalizing and externalizing problems from middle to late childhood. Child Development, 61, 2004-21.

Kagan, J. (1980). Perspectives on continuity. In O. G. Brim, Jr. \& J. Kagan (eds.), Constancy and change in buman development, pp. 26-74. Cambridge, MA: Harvard University Press.

Kliegl, R., Smith, J. \& Baltes, P. B. (1989). Testing-the-limits and the study of adult age differences in cognitive plasticity and of mnemonic skill. Developmental Psychology, 25, $247-56$.

Knopf, M., Kolodziej, P. \& Preussler, W. (1990). Der ältere Mensch als Experte Literaturübersicht über die Rolle von Expertenwissen für die kognitive Leistungsfähigkeit im höheren Alter. Zeitscbrift für Gerontopsychologie und-psycbiatrie, 4, $233-48$.

Kohlberg, L., LaCrosse, I. \& Ricks, D. (1972). The predictability of adult mental health from childhood behavior. In B. B. Wolman (ed.), Manual of child psycbopatbology, pp. 1217-1284. New York: McGraw-Hill.

Magnusson, D. (1981). Some methodology and strategy problems in longitudinal research. In F. Schulsinger, S. A. Mednick \& J. Knop (eds.), Longitudinal researchmetbods and uses in behavioral science, pp. 192-215. Boston: Martinus Nijhoff Publishing.

Magnusson, D. (1988). Individual development from an interactional perspective: a longitudinal study. Hillsdale, NJ: Erlbaum.

Magnusson, D. \& Bergman, L. R. (1990). A pattern approach to the study of pathways from childhood to adulthood. In L. N. Robins \& M. Rutter (eds.), Straight and devious pathways from childbood to adulthood, pp. 101-115. Cambridge: Cambridge University Press.

Parker, J. G. \& Asher, S. R. (1987). Peer relations and later personal adjustment: are lowaccepted children at risk? Psycbological Bulletin, 102, 357-89.

Rutter, M. (1987). Continuities and discontinuities from infancy. In J. D. Osofsky (ed.), Handbook of infant development, vol. 2, pp. 1256-1296. New York: Wiley.

Salthouse, T. A. (1984). Effects of age and skill in typing. Journal of Experimental 
Psychology: General, 113, 345-71.

Schaie, K. W. (1983). The Seattle Longitudinal Study. In K. W. Schaie (ed.), Longitudinal studies of adult psychological development, pp. 64-135. New York: Guilford.

Schaie, K. W. (1989). Individual differences in rate of cognitive change in adulthood. In V. L. Bengtson and K. W. Schaie (eds.), The course of later life. Research and reflections, pp. 65-85. New York: Springer.

Schaie, K. W. (1990). Intellectual development in adulthood. In J. E. Birren \& K. W. Schaie (eds.), Handbook of the psychology of aging, (3rd ed.), pp. 291-309. San Diego: Academic Press.

Schneider, W. (1989). Problems of longitudinal studies with children: Practical, conceptual, and methodological issues. In M. Brambring, F. Lösel and H. Skowronek (eds.), Children at risk: assessment, longitudinal research, and intervention, pp. 313-335. New York: De Gruyter.

Schneider, W. \& Edelstein, W. (1990). Inventory of European longitudinal studies on the behavioral and medical sciences. Berlin: Max-Planck-Institut für Bildungsforschung.

Schneider, W. \& Sodian, B. (1991). A longitudinal study of young children's memory behaviour and performance in a sort-recall task. Journal of Experimental Child Psychology, 51, 14-29.

Schneider, W., Knopf, M. \& Weinert, F. E. (1989). Interrelationships among measures of memory and measures of intellectual development. In F. E. Weinert \& W. Schneider (eds.), The Munich Longitudinal Study on the Genesis of Individual Competencies (LOGIC). Report No. 6: psycbological development in the preschool years: longitudinal results of wave one to three, pp. 108-113. Munchen: Max Planck Institute for Psychological Research.

Siegler, R. S. \& Crowley, K. (1991). The microgenetic method: a direct means for studying cognitive development. American Psychologist, 46, 606-20.

Siegler, R. S. \& Jenkins, E. (1989). How cbildren discover strategies. Hillsdale, NJ: Erlbaum.

Staszewski, J. J. (1990). Exceptional memory: the influence of practice and knowledge on the development of elaborative encoding strategies. In W. Schneider \& F. E. Weinert (eds.), Interactions among aptitudes, strategies, and knowledge in cognitive performance, pp. 252-285. New York: Springer-Verlag.

Verdonik, F. \& Sherrod, L. R. (1984). An inventory of longitudinal research on childbood and adolescence. New York: Social Science Research Council.

Weinert, F. E. (1990). Entwicklungsgenetik und Sozialisationsforschung: Widersprüche, Probleme und Perspektiven. In Entwicklung und Lernen - Beiträge zum Symposium anläßlich des 60. Geburtstages von Wolfgang Edelstein, pp. 13-36. Berlin: MPI für Bildungsforschung.

Weinert, F. E. (1991). Stability and variability in change of memory functions in childhood. Paper presented at the International Conference on Memory, Lancaster, July 1991.

Weinert, F. E. \& Schneider, W. (eds.) (1989a). The Munich Longitudinal Study on the Genesis of Individual Competencies (LOGIC), Report No. 6: Psychological development in the preschool years: Longitudinal results of wave one to three. München: Max Planck Institute for Psychological Research.

Weinert, F. E. \& Schneider, W. (eds.) (1989b). The Munich Longitudinal Study on the Genesis of Individual Competencies (LOGIC), Report Nr. 5: Results of wave three (Technical Report). München: Max Planck Institute for Psychological Research.

Weinert, F. E. \& Waldmann, M. R. (1986). How do the gifted think: intellectual abilities and cognitive processes. In A. J. Cropley, K. K. Urban, H. Wagner \& W. 
Wieczerkowski (eds.), Giftedness: A continuing worldwide cballenge, pp. 49-64. New York: Trillium Press.

Weinert, F. E., Schneider, W. \& Knopf, M. (1988). Individual differences in memory development across the life span. In P. B. Baltes, D. L. Featherman \& R. M. Lerner (eds.), Life-span development and behavior, vol. 9, pp. 39-85. Hillsdale, NJ: Erlbaum.

Weiss, B., Weisz, J. R. \& Bromfield, R. (1986). Performance of retarded and nonretarded persons on information processing tasks: tests of the similar structure hypotheses. Psychological Bulletin, 100, 157-75.

Weisz, J. R. \& Yeates, K. O. (1981). Cognitive development in retarded and nonretarded persons: Piagetian tests of the similar structure hypothesis. Psychological Bulletin, 90, 153-78.

Wohlwill, J. F. (1973). The study of bebavioral development. New York: Academic Press. 